\title{
Association of Explosive Power and Agility among Cricketers of State Level
}

\author{
Anagha Ghosalkar ${ }^{1}$, Shishir Nigam ${ }^{2}$, Preeti Saini ${ }^{3}$ \\ ${ }^{1}$ Masters Student, ${ }^{2}$ Assistant Professor, ${ }^{3}$ Assistant Professor, Department of Physiotherapy, Faculty of Applied \\ Science, Manav Rachna International Institute of Research \& Studies, Faridabad, Haryana, India-121001
}

\begin{abstract}
Often cricket is stated as an aerobic sport however when broken down the game is played by the players performing at various speeds and intensities-jumping, sprinting, catching, diving, majority of the play is in intervals and the activity does not lasts for long periods of time (e.g.; batting, bowling, fielding, wicket keeping, making a run).Purpose of the study is to determine association between explosive power agility in state level cricket players. Previous studies have investigated physical performances with respect to injury incidence and prevention. In this study physical aspects such as power, agility and anaerobic fitness shall be considered. Also due to paucity of evidences and studies on this literature it is important to find an association between the explosive power, agility among cricket players of state level. Total 100 male state level cricketers from different cricket academies were included in the study. Subjects with age group of 16-23 were taken in the study. Screening and assessment protocol were followed to select participants. Performance tests were measured. Explosive power with vertical jump test, agility with run a 3 test. Result of study showed:
\end{abstract}

1. Correlation between explosive power and agility was $-.305^{* *}$ and it was significant at .002 .

Present study concluded that explosive power is negatively correlated with agility.

Keywords: Fast twitch muscle type, anaerobic capacity, fitness testing, professional cricket, performance.

\section{Introduction}

Cricket is a sport that is played by millions from all the corners of the globe. All over the world three formats are practised at the elite level: Test, One day, and Twenty $-20 .^{21}$ Cricket involves large physiological demands of the human body, muscular strength and endurance, CVS endurance, speed, agility, power, flexibility etc. Often cricket is stated as an aerobic sport however when broken down the game is competed by the athletes playing at a range of speeds and intensities-jumping, sprinting, catching, diving, greater part of the sport is in pauses and the movements does not lasts for long periods of time (e.g.; batting, bowling, fielding, wicket keeping, making a run).

Cricket involves sudden movements which are often slow and fast. A professional player is expected to perform a large number of sprints, jumps, lunges and rapid directional changes. As well as another characteristic of cricket is execution of sporadic or fast movements of moderate to high intensity relate to repetitive actions of short duration but greater intensity as it occurs in other sports with similar characteristics like (squash etc). The shorter game formats tend to be more physically intensive when related to match duration, incorporating more maximal sprints when fielding, bowling, and batting. As a result of these demands, running speed, agility and power or strength has become an essential athletic quality for cricketers and therefore must be assessed correctly. Appropriate speed \& agility assessments can provide an indicator of an athlete's level of ability, and be used to monitor physical development.

Leg strength and speed (power) are vital for cricketers. These two elements to influence the speed and agility necessarily meant for fielding, wicket keeping and 
running between wickets. It is even essential for bowlers because it helps them monitor and practice their ability to absorb the forces experienced by the legs during a delivery. ${ }^{4}$ Strength of the muscles of lower extremity upper extremity and trunk is of utmost importance for the execution of strokes of the ground. ${ }^{32}$

Cricket is termed as an interval sport with equally anaerobic and aerobic components. ${ }^{26}$ At advanced ability intensities, technical performance may be reduced by physical attributes, physical fitness and performance qualities. $^{31}$ Also, cardiorespiratory fitness in terms of max $\mathrm{O} 2$ uptake $\left(\mathrm{VO}_{2} \max \right)$ reflects physical fitness of a person hence; $\mathrm{VO}_{2}$ max is the single preeminent measure of cardiorespiratory capacity and is considered as a bench mark to quantity CVS functional capacity and aerobic fitness.

There are various study conducted to assess agility and explosive strength but there are lack of literature studying association between explosive power agility in cricket player

\section{Methodology}

Subjects were taken after signing informed consent including 100 male state level cricket players with age group of 16-23 with normal BMI $(<25)$. who fulfilled the inclusion criteria playing for at least 1 year at state levelPlayers were asked to perform general warmup for 20 mins 2 performance tests were measured. Explosive power using vertical jump test. Agility using run a 3 test. Data will be collected from academy in Faridabad and Delhi .Assessment form was filled (details pertaining to sport, dominance, level of playing position etc.)

The demographic details are recorded and information about subject is collected in assessment formheight (cms) and weight $(\mathrm{kg})$ and BMI was calculated. After completing the assessment form the testing for vertical jump, run a 3 test was done after a general warmup. Height was measured using a wall mounted stadiometer with a horizontal head board. Players stood barefoot, feet together and stand tall. Height and weight was recorded to a precision of $0.1 \mathrm{cms}$ and $0.1 \mathrm{~kg}$ respectively.

Sargent chalk jump test: Subjects stood with one side against a wall, heels together and held a one inch piece of chalk in the hand nearest to the wall. With the heels together the subject was asked to make mark as high as possible on the wall. Then were required to jump as high as possible to make another mark on the wall, the score was calculated at the distance in centimetres between the reach mark and the highest jump mark attained by the subject.

Run a three test: To assess agility, "Run a three" protocol of Bourdon et al was chosen. The subjects were asked to warm up prior to the test and allowed at least two trials at sub maximal pace. The test was performed on a cricket wicket or crease of $17.68 \mathrm{~m}$ or 22 yards respectively. Subjects were instructed to presume the starting position, with one foot behind the popping crease line and cricket bat in hand and with knee pads, physically and mentally ready to take run. No cue was given to begin the test. The timing began when the subject's rare foot left the ground and finished as the bat crossed the popping crease line at the end of the third run. Subjects had to perform three trials with the fastest average time was recorded as the best score. A rest interval of $\geq 5$ minutes was given between trials. The average time from the two stopwatches was recorded to the nearest 0.1 second.

The statistical tests were applied which includes mean, standard deviation, Karl Pearson correlation for assessing the correlation between agility and explosive strength,.SPSS 21 version was used as a statistical tool. Relationship between the test variables were determined by using bivariate correlation.

In this study the level of significance was set as $\mathrm{p} \leq$ 0.05 .

\section{Results}

The descriptive values of the sample group are shown in the table below:

Descriptive characteristics of Age and BMI (Mean \pm standard deviation)

\begin{tabular}{|l|l|}
\hline Variables & Males $(\mathbf{N}=\mathbf{1 0 0})$ \\
\hline Age $($ years $)$ & $17.49 \pm 1.68$ \\
\hline BMI $\left(\mathrm{kg} / \mathrm{m}^{2}\right)$ & $22.76 \pm 2.61$ \\
\hline
\end{tabular}

Descriptive statistics of Explosive power test.

\begin{tabular}{|l|l|}
\hline Variable & Mean \pm SD \\
\hline Vertical jump height $(\mathrm{cms})$ & $53.1 \pm 7.52$ \\
\hline
\end{tabular}


Descriptive statistics of Agility test.

\begin{tabular}{|l|c|}
\hline Variable & Mean \pm SD \\
\hline Run a 3 test $(\mathrm{sec})$ & $10.6 \pm .563$ \\
\hline
\end{tabular}

Correlation between explosive power (vertical jump height) and agility (Run a 3 test).

\begin{tabular}{|l|l|c|}
\hline Variables & r-value & p-value \\
\hline Vertical jump height \& Run a 3 test score & $-.305^{* *}$ & .002 \\
\hline
\end{tabular}

Scatter gram of vertical jump height score and Run a 3 test score.

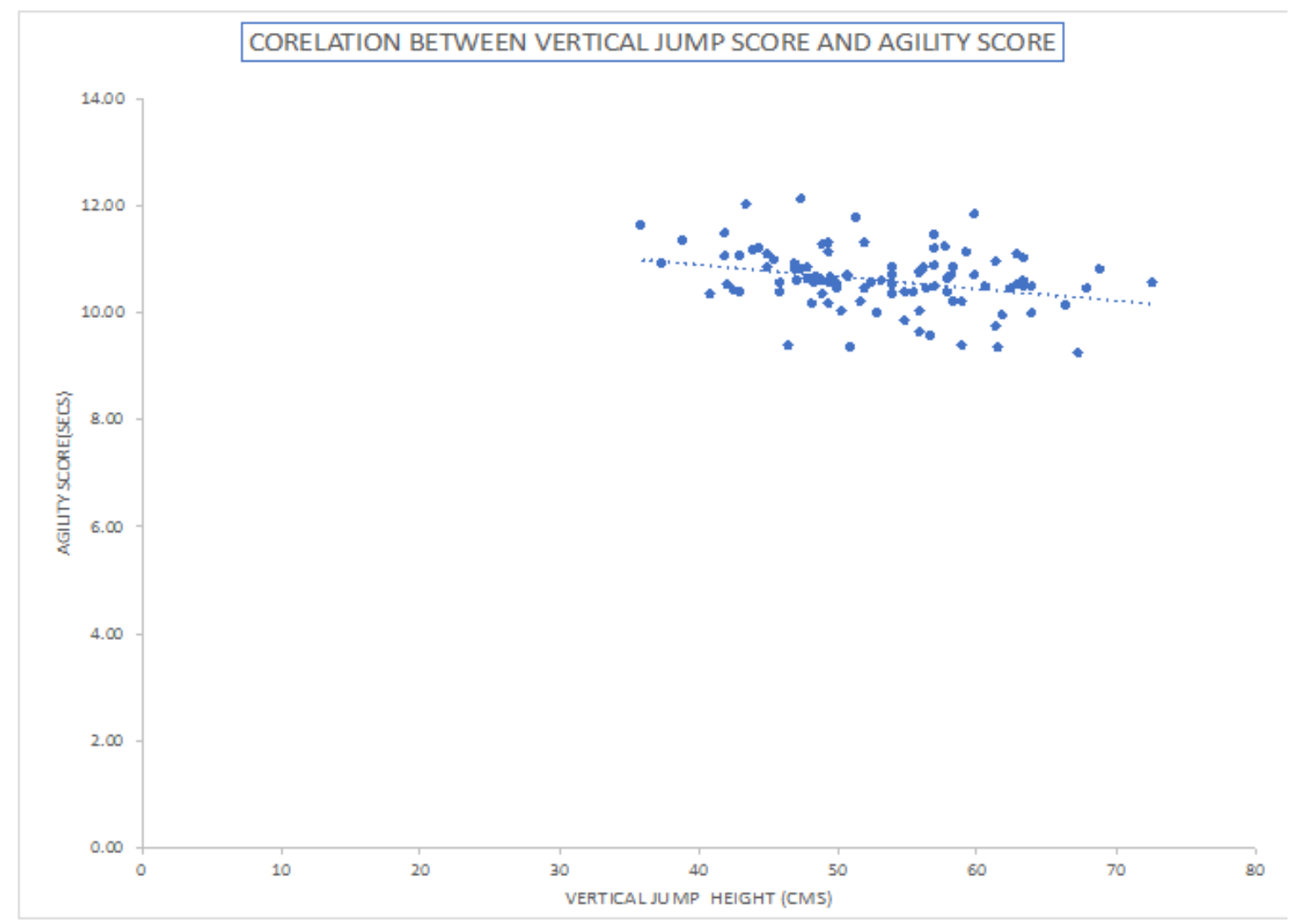

\section{Conclusion and Discussion}

Study was to assess the explosive power of the cricket players. According to the result of the present study mean scores of explosive power $(\mathrm{cms})$ were 53.10. Similar studies Gabbet et al stated there was limited research pertaining to the enhancement of athletic performance although he stated that a study on professional rugby players had a better or significant impact of lower body explosive power and speed on their physical playing performance. On the contrary longitudinal studies on rugby players found no differences in explosive strength as a marker of physical performance. ${ }^{23}$ A study by Carr et al on elite cricketers measuring their explosive power over a range of season showed improvements in lower body power scores overall the seasons. ${ }^{6}$ Studies by Johnstone on explosive power differences in batsman and bowlers showed negligible differences among them. Jakovl jev through his studies concluded "explosive power is an essential pre requisite for sports that demand explosiveness and fast maximal energy production and finds need to be incorporated for planning and training, performance prediction and talent identification in various sports". ${ }^{19}$ Castagna has also further layed emphasis on the varying role of explosive power in various sports like cricket and basketball which is 
essential for improving their performance. ${ }^{7}$ Secondly study was focused to assess agility of cricket players. According to results of the present study the mean scores of agility (secs) were 10.6. A study stated role and efficacy of agility in cricket is increased with implementation of a 6 week specific exercise programme. ${ }^{31}$ Similar study done by Shrivastava (2015) confirmed specialized exercises help in increase of cricket specific agility in male cricket players. Agility is the most crucial factor influencing movement also as important to influence motor action. Boora (2016) also emphasised agility has a distinctive role in cricket to execute competent footwork and rapid changes in body position. Various studies done to evaluate variable of physical fitness i.e. agility in batsmen and bowlers reviewed batsmen had better agility that had an influence on physical performance. According to a study on effect of different types cricket batting pads on running and turning speed showed no significant differences in running or turning speed due to the influence of different cricketing pads. ${ }^{24}$

Third objective of study was to determine the association between explosive power and agility of cricket players. Results of the present study stated explosive power showed moderate negative correlation $\left(\mathrm{r}=-.305^{* *}\right)$ and was highly significant at $(\mathrm{p}=.002)$ with agility and the result states that with improved vertical jump height scores there is an eventual decrease in time required to complete 3 consecutive runs. A study done to assess role of explosive power of male footballers showed explosive power was the most dominating variable for improving agility. ${ }^{28}$ Numerous studies by other researchers have same results which supported this study. Conducted similar study measuring these variables on basketball players. ${ }^{16}$ Study stated that leg strength and power were most significant factors required by cricketers especially fielders such that it contributed to further increase in agility and speed required for fielding. ${ }^{22}$ Studies have supported that with specific 6-8 week exercise programme including plyometric, resistance and interval training has shown to improve the explosive power and impact the influence of agility desirable for athletic performance. Exercises have an effect on anaerobic pathway ATP-Pcr system and neuromuscular adaptions that cause improved balance and body position that favours on improving explosive power and agility. Also due to explosive nature of the sport there is definite need to develop power for increasing run up speed and agility. ${ }^{12}$

\section{Conclusion}

While computing the correlation coefficient between Explosive power, Agility the present study concluded that explosive power is negatively correlated with agility i.e. with peak score of jump height there is decrease in time taken to complete 3 runs by the players which stated that good anaerobic power contributes in improving the agility performance necessary for the cricket players. Findings of the study can be used by physiotherapist, coaches as well as trainers or the sports professionals to train the team in relation to certain particular aspects that needed to be improved for the team to achieve better performance.

Ethical clearance taken from: Manav Rachna International Institute of Research and Studies committee.

\section{Source of Funding: Self}

\section{Conflict of Interest: Nil}

\section{References}

1. Alemdaroğlu U. The relationship between muscle strength, anaerobic performance, agility, sprint ability and vertical jump performance in professional basketball players. Journal of human kinetics. 2012 Mar 1;31:149-58.

2. Bangsbo J, Iaia FM, Krustrup P. The Yo-Yo intermittent recovery test. Sports medicine. 2008 Jan 1;38(1):37-51.

3. Bellar D, Hatchett A, Judge LW, Breaux ME, Marcus L. The relationship of aerobic capacity, anaerobic peak power and experience to performance in CrossFit exercise. Biology of sport. 2015 Dec;32(4):315.

4. Bourdon P, Savage B, Done R. Protocols for the physiological assessment of cricket players. Physiological Tests for Elite Athletes. Champaign, USA: Human Kinetics. 2000:238-43.

5. Callaghan SJ, Lockie RG, Jeffriess MD, Nimphius S. Kinematics of faster acceleration performance of the quick single in experienced cricketers. The Journal of Strength \& Conditioning Research. 2015 Sep 1;29(9):2623-34.

6. Carr C, McMahon JJ, Comfort P. Changes in strength, power, and speed across a season in English county cricketers. International journal of sports physiology and performance. 2017 Jan 


$$
\text { 1;12(1):50-5. }
$$

7. Castagna C, Chaouachi A, Rampinini E, Chamari $\mathrm{K}$, Impellizzeri F. Aerobic and explosive power performance of elite Italian regional-level basketball players. The Journal of Strength \& Conditioning Research. 2009 Oct 1;23(7):1982-7.

8. Christie CJ. The physical demands of batting and fast bowling in cricket. ISBN; 2012 Feb 17.

9. Cummins C, Orr R, O'Connor H, West C. Global positioning systems (GPS) and microtechnology sensors in team sports: a systematic review. Sports medicine. 2013 Oct 1;43(10):1025-42.

10. Dragijsky M, Maly T, Zahalka F, Kunzmann E, Hank M. Seasonal variation of agility, speed and endurance performance in young elite soccer players. Sports. 2017 Mar;5(1):12.

11. Duffield R, Carney M, Karppinen S. Physiological responses and bowling performance during repeated spells of medium-fast bowling. Journal of Sports Sciences. 2009 Jan 1;27(1):27-35.

12. Esteve-Lanao Jo, San Juan AF, Earnest CP, Foster C, Lucia A. How do endurance runners actually train? Relationship with competition performance. Medicine \& Science in Sports \& Exercise. 2005 Mar 1;37(3):496-504.

13. Fanchini $M$, Castagna $C$, Coutts AJ, Schena F, McCall A, Impellizzeri FM. Are the Yo-Yo intermittent recovery test levels 1 and 2 both useful? Reliability, responsiveness and interchangeability in young soccer players. Journal of sports sciences. 2014 Dec 14;32(20):1950-7.

14. Gharbi Z, Dardouri W, Haj-Sassi R, Chamari K, Souissi N. Aerobic and anaerobic determinants of repeated sprint ability in team sports athletes. Biology of sport. 2015 Sep;32(3):207.

15. Gumay JR, Dlis F, Maharani in. Lay up shoot exercise skill model of basketball based game for beginner age 12-14 years. Journal Physical Education, Health and Recreation.;3(1):29-35.

16. Harbili S. Relationship between lower extremity isokinetic strength and anaerobic power in weightlifters, basketball and soccer players. Isokinetics and Exercise Science. 2015 Jan 1;23(2):93-100.

17. Herridge-MSc R, Turner-PhD A. Monitoring changes in power, speed, agility and endurance in elite cricketers during the off-season. population. 2017;14:15.
18. Jakovljević DK, Eric M, Jovanovic G, Dimitric G, Cupic MB, Ponorac N. Explosive muscle power assessment in elite athletes using wingate anaerobic test. Revista Brasileira de Medicina do Esporte. 2018 Mar;24(2):107-11.

19. Johnstone JA, Ford PA. Physiologic profile of professional cricketers. The Journal of Strength \& Conditioning Research. 2010 Nov 1;24(11):29007.

20. Kathayat LB, Kumar A. A Study of Anaerobic Fitness of Cricket Players in Punjab. Journal of Exercise Science \& Physiotherapy. 2018;14(1).

21. Kathayat LB, Kumar A. Haemodynamic and VO2max Profile of Punjabi Cricket Players. Journal of Exercise Science \& Physiotherapy Vol. 2018;14(2).

22. Lamani CG, Tiwari PS. A study of morphological of junior and senior cricket players and specific motor fitness of bowlers and batsman of Goa.

23. Lockie RG, Callaghan SJ, Jeffriess MD. Analysis of specific speed testing for cricketers. The Journal of Strength \& Conditioning Research. 2013 Nov 1;27(11):2981-8.

24. MacDonald D, Cronin J, Mills J, McGuigan M, Stretch R. A review of cricket fielding requirements. South African Journal of Sports Medicine. 2013;25(3):87-92.

25. Nimphius S, Callaghan SJ, Bezodis NE, Lockie RG. Change of direction and agility tests: Challenging our current measures of performance. Strength \& Conditioning Journal. 2018 Feb 1;40(1):26-38.

26. Noakes TD, Durandt JJ. Physiological requirements of cricket. Journal of sports sciences. 2000 Jan 1;18(12):919-29.

27. Pandey AK, Chaubey DK. Relationship between explosive strength and agility of Football male players. International Journal of Applied Research. 2015;1(10):303-5.

28. Percival J, Percival L, Taylor JW. The complete guide to total fitness. Methuen; 1977.

29. Petersen CJ, Pyne DB, Dawson BT, Kellett AD, Portus MR. Comparison of training and game demands of national level cricketers. The Journal of Strength \& Conditioning Research. 2011 May 1;25(5):1306-11.

30. Potteiger JA, Smith DL, Maier ML, Foster TS. Relationship between body composition, leg 
strength, anaerobic power, and on-ice skating performance in division I men's hockey athletes. The Journal of Strength \& Conditioning Research. 2010 Jul 1;24(7):1755-62.

31. Praveen K, Ansi N. Effect of selected exercises on explosive strength, speed, endurance and agility of medium fast bowlers in cricket.

32. Robert GL, Callaghan SJ, Jeffriess MD. Acceleration kinematics in cricketers: implications for performance in the field. Journal of sports science \& medicine. 2014 Jan;13(1):128.

33. Saini R. Comparative study of psychomotor components between the athletes of individual and team sports. Unpublished Master Thesis. PU Chandigarh. 1996.

34. Scanlan AT, Berkelmans DM, Vickery WM, Kean CO. A review of the internal and external physiological demands associated with batting in cricket. International journal of sports physiology and performance. 2016 Nov 1;11(8):987-97.
35. Stojanovic MD, Ostojic SM, Calleja-González J, Milosevic Z, Mikic M. Correlation between explosive strength, aerobic power and repeated sprint ability in elite basketball players. Journal of Sports Medicine and Physical Fitness. 2012 Aug 1;52(4):375.

36. Stretch R, Buys F, Toit ED, Viljoen G. Kinematics and kinetics of the drive off the front foot in cricket batting. Journal of Sports Sciences. 1998 Jan 1;16(8):711-20.

37. Taheri E, Nikseresht A, Khoshnam E. The effect of 8 weeks of plyometric and resistance training on agility, speed and explosive power in soccer players. European Journal of Experimental Biology. 2014;4(1):383-6.

38. Taskin C. Aerobic Capacity and Anaerobic Power Levels of the University Students. Higher Education Studies. 2016;6(2):76-83.

39. Taskin H. Effect of circuit training on the sprintagility and anaerobic endurance. The Journal of Strength \& Conditioning Research. 2009 Sep 1;23(6):1803-10. 